\title{
Improving the Altman Method for Assess the Creditworthiness of Enterprises with Economic Indicators in the Form of Fuzzy Numbers
}

\author{
Alevtina Shatalova ${ }^{1}$, Konstantin Lebedev ${ }^{1}$, Igor Shevchenko ${ }^{2}$, Boureima Bamadio ${ }^{3}$ \\ ${ }^{1}$ Department of Applied Mathematics, Kuban State University, Krasnodar, Russia \\ ${ }^{2}$ Faculty of Economics, Kuban State University, Krasnodar, Russia \\ ${ }^{3}$ Faculty of Economics and Management, University of Social Sciences and Management of Bamako, Mali, Bamako
}

Email address:

al-shatalova@yandex.ru (A. Shatalova), klebedev.ya@yandex.ru (K. Lebedev), dean@econ.kubsu.ru (I. Shevchenko), anadama@mail.ru (B. Bamadio)

\section{To cite this article:}

Alevtina Shatalova, Konstantin Lebedev, Igor Shevchenko, Boureima Bamadio. Improving the Altman Method for Assess the Creditworthiness of Enterprises with Economic Indicators in the Form of Fuzzy Numbers. Engineering Mathematics.

Vol. 4, No. 1, 2020, pp. 10-13. doi: 10.11648/j.engmath.20200401.12

Received: August 13, 2019; Accepted: September 6, 2019; Published: May 28, 2020

\begin{abstract}
The article describes the Altman Five-factor Model to assess the creditworthiness of the enterprise with the apparatus of the theory of fuzzy sets. There were two improvements. The early method used the square integral approximation for the accurately calculating of the quantitative assessment of creditworthiness and the apparatus of fuzzy sets for ordering the sets according to the degree of confidence of the probability obtained. The new method described in this article is expanded by presenting the input data as triangular fuzzy numbers. This article describes the simulation of the credit assessment procedure and the possibility of functioning of the model as well. This approach helps to adequately assess the creditworthiness of the enterprise, also to make it possible to predict the change in the result of the model due to possible errors in the input data. The results were tested at the Krasnodar cryptic plant.
\end{abstract}

Keywords: Assessment of the Creditworthiness, Altman Model, Fuzzy Sets, Membership Function, Simulation, Decision-making Under Uncertainty, Errors in the Financial Statements

\section{Introduction}

The problem of timely repayment of loans is relevant for the activities of any lending organization (Bank). Despite the presence of a large number of various techniques (D. Fulmer; R. Taffler; W. beaver; L. Dontsova; A. Sheremet., R. Saifulin, E. Negashev; P. Fo-Mina; O. Zaitseva; G. Savitskaya; and others) $[1,3,5,7,9,12-14,16,21,22]$, however, in real economic practice, there is no universal methodology for assessing the creditworthiness of an enterprise that allows to assess the creditworthiness of the enterprise. In the modern practice of financial and economic activity of foreign firms to assess the probability of bankruptcy and the adoption of the legal assessment of the creditworthiness of the enterprise the most widely used models developed by E. Altman and W. Beaver [19, 21]. The first Russian experience of using Altman's approach is the developed Davydova-Belikov model [3]. The applicability of this approach to Russian realities is ensured by recalculation of the coefficients $k_{i}$ $(\mathrm{i}=1, \ldots, 5)$ in the Altman model [9].

In practice, when assessing creditworthiness using the Altman model, it is often necessary to make a decision in the conditions of inaccuracy of the initial data. In such situations, special methods can be used to deal with uncertainties. The field of mathematics dealing with inaccurate information is called the theory of fuzzy sets $[6,10]$. Expert systems built within the framework of this theory have proven themselves not only in the evaluation of quantitative but also linguistic uncertainties [15]. Currently, the theory of fuzzy sets is a well-developed scientific discipline, which is of great practical importance $[4,8,10,11,15,18,23]$.

Recently, simulation modeling has become increasingly popular among mathematical approaches to reproduce the studied processes or phenomena, which helps to take into 
account the influence of various parameters, to provide a rationale for the most rational solution for the expert, to accumulate fairly stable statistics for assessing the reliability of the final solution [17].

\section{Method}

The purpose of this work is to improve the developed in [20] methodology for assessing the creditworthiness of the enterprise, taking into account its fuzzy economic indicators for a particular enterprise, when the value of the Altman function changes in a narrow range of economic parameters inherent in a particular enterprise, using the apparatus of the theory of fuzzy sets, their modeling and Altman model. The work is fundamental, it is a natural, logical continuation of the work [20].

In this paper we will use the five-factor Altman model ( $z$ model), which allows us to assess the possibility of bankruptcy of the enterprise, which, in relation to the us economy, has the form [19]:

$$
z=1.2 k_{1}+1.4 k_{2}+3.3 k_{3}+0.6 k_{4}+1.0 k_{5},
$$

Where coefficients $k_{1}$ is the ratio of working capital to total assets, $k_{2}$ is the ratio of retained earnings to the amount of assets, $k_{3}$ is the ratio of profit before interest on the amount of assets, $k_{4}$ is the ratio of the market value of equity to borrowed capital, $k_{5}$ sales of assets. Weights at coefficients were calculated on the basis of multiple discriminant analysis (MDA-analysis) in relation to the us economy.

The obtained value of $z$ function allows to determine the probability of $p(z)$ bankruptcy of the enterprise.

According to the Altman model, the calculated value of $\mathrm{z}$ is compared to one of the sets $A_{i}(i=1,2,3,4)$ (Figure 1) intervals of probability of bankruptcy of the enterprise. If $0 \leq z<1.81$ - the probability of bankruptcy is "the probability of bankruptcy is high", if $1.81 \leq z<2.77$ - the probability $p(z)$ of bankruptcy, i.e. "the probability of bankruptcy is average", if $2.77 \leq z<2.99$, then "the probability of bankruptcy is not high", if $z \geq 2.99$, then the probability of bankruptcy is small enough $(\varepsilon \rightarrow 0$ if $z \rightarrow \infty)$ and is considered approximately equal to zero.

\section{Result}

According to the classical theory of Altman with the found $\mathrm{z}$ value obtained is not the exact value of the probability of bankruptcy, and the range of the probabilities of $A_{i}(i=1,2,3$, 4). In this model, Altman's probability of bankruptcy is a discontinuous multivalued function of the parameter $z$. To present it as a continuous function, in which a specific value of the argument $z$ corresponds to a specific value of $p$, two optimization functions are determined by the minimum $f_{1}(z)=\min _{\forall z} p(z) \quad$ and maximum $f_{2}(z)=\max _{\forall z} p(z)$ $\left(f_{1}(z)<f_{2}(z)\right)$ and the problem of the integral mean square approximation of Altman sets by a polynomial of sufficiently high $\left(6^{\text {th }}\right.$ degree $)$ is solved, presented in the form $L_{n}(z)=\sum_{i=0}^{n}\left(a_{i} z^{i}\right)$ of a segment of values $z \in\left[0, z_{4}\right], z_{4}=3.5$ (Figure 1), because if $z \geq 2.99$, it is zero $p \in A_{4}=[0, \varepsilon]$ [20]. Lower degrees do not approximate $f_{1}(x)$ and $f_{2}(x)$ with sufficient accuracy for practice, and higher $n>7$ is used irrationally [2].

The construction of the function $L_{6}(z)$ makes it possible to obtain the value of $p$ in areas that lie outside the sets $A_{i}$, i.e. in the ranges $T_{i}(i=1,2,3)$ (Figure 1). The set $T=\bigcup_{k=1}^{4} T_{k}$ is an addition to $A=\bigcup_{k=1}^{4} A_{k}$ i.e. $T \bigcup A=[0,1]$.

Calculating the value of $z$ by the Altman (1) method and calculating $p$ by the formula $L_{6}(z)$ does not always make it possible to attribute the calculated value of $\mathrm{p}$ to one of the sets of $A_{i}$, that is, to one of the cases $p \in A_{1}=[0.8,1.0]$, $p \in A_{2}=[0.35,0.50], p \in A_{3}=[0.15,0.20], p \in A_{4}=[0,0.05]$. For example, if $L_{6}(z)=\mathrm{p}=0.7$, then $p$ can be attributed to both $A_{1}$ and $A_{2}$.

The need to attribute the obtained value of $p(z)$ to one of the nearby $A_{i}$ Altman sets can be solved in different ways. We solve this problem using the methods of fuzzy set theory [20], for which the simplest piecewise linear continuous membership functions are constructed.

If we assume that the sets $A_{i}$ is clear, then the expert will have to make a decision about the likelihood of bankotsu company. Indeed, if the probability value $p$ found by the Altman model using $L_{6}(z)$ falls into one of the sets $A_{i}$, the value of the function of appropriateness will be equal $\mu=1$. In this case, the probability of bankruptcy of the enterprise is attributed to the value obtained $p=L_{6}(z) \in A_{i}$. But, if $p=L_{6}(z) \notin A_{i}$, i.e. does not fall into any of the four intervals $A_{i}$, the value of the membership function $\mu=0$ and the number $i$ is not defined. In this case, we assume that $A_{i}$ are contained in fuzzy sets $A_{i} \in X_{i}$ and the problem arises for the expert to determine the number of the set $A_{i}$ by calculating the value $0<\mu<1$. To solve this problem in [20] introduced by a certain procedure, fuzzy sets $X_{i}$ are given preference functions $\mu_{\tilde{X}_{i}}(u): U \rightarrow \mu \in M=[0,1] \in R$, where $\mu_{\widetilde{X_{i}}}(p)$ - a function (measure) belonging to the classification of the enterprise to the resulting set $\widetilde{X}_{i}$ in the system ordered by the degree of fuzzy (trust). After calculating $z, p(z)$, selecting $\tilde{X}_{i}$ and calculating the membership measure $\mu_{\widetilde{\mathrm{x}}_{\mathrm{i}}}(\mathrm{p})$, the sets $\tilde{X}_{i}$ are evaluated in terms of the degree of fuzziness. Trust in the judgment of the possible bankruptcy of the enterprise increases from left to right in a row $\tilde{X}_{2} \succ \tilde{X}_{1} \succ \tilde{X}_{3} \succ \tilde{X}_{4}$.

The membership function $\mu_{A}(u)$ is a function whose domain is new $U,(u \in U)$, and whose domain of values $\mu_{A}(u)$ is the unit interval $[0 ; 1][6]$. The higher the value $\mu_{A}-$ the higher the degree of membership of the media element $U$ 
to the fuzzy set $A$. In our case, we choose $U=\{X, 0 \leq X \leq 1\}$ as the carrier on which the set of $A_{i}$ where is the probability of bankruptcy of the enterprise corresponding to the value found by using equation (1). On this medium, we define the functions of belonging: for the value $p_{1}-\mu_{\widetilde{X}_{1}}(p), p_{2}-$ $\mu_{\tilde{X}_{2}}(p), p_{3}-\mu_{\tilde{X}_{3}}(p), p_{2}-\mu_{\tilde{X}_{4}}(p)$, the first of them corresponds to the odd-to whom a subset $\tilde{X}_{1}$, the second$\tilde{X}_{2}$, the third- $\tilde{X}_{3}$, and the fourth- $\tilde{X}_{4}$, where $\tilde{X}_{1}-$ "the possibility of Bank-rotation is high", $\widetilde{X}_{2}-$ "the possibility of bankruptcy is average", $\widetilde{X}_{3}-$ "the possibility of bankruptcy is not-large", $\tilde{X}_{4}-$ "the possibility of bankruptcy is small".

\section{Discussion}

In work [20] the scheme of application of Altman model in all range of change of $z$ from 0 to 3, 5 representing four-stage sequence of processing of the values of parameters $\mathrm{z}$ received at simulation is offered. In this paper we take into account the fuzzy coefficients and then the scheme will be supplemented with a new block on the left, Figure 1.

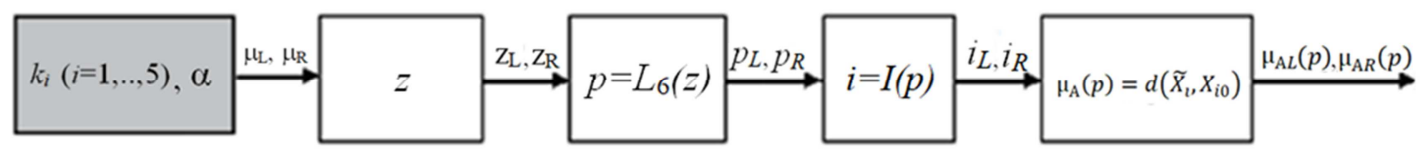

Figure 1. The scheme of the sequence of calculations of the enterprise creditworthiness assessment.

The new block calculates the value-fuzzy parameters based on the data of a particular enterprise and the parameter $\mathrm{z}$ changes in a small neighborhood of a certain point.

Upon receipt of the main economic indicators from the financial statements, the coefficients $\mathrm{k}_{\mathrm{i}}$ are calculated, which are modeled as triangular fuzzy numbers with a set of $\alpha$ levels. At a fixed level $0<\alpha<1$. Based on this data, the value of the Altman $\mathrm{z}$ function is calculated.

At different values of $\alpha \in[0 ; 1]$ the fuzzy set is represented as sets of $\alpha$-level (alpha-slice, alpha-section), i.e. in the form. Then, for example, for a fuzzy number $\mathrm{k}_{1}=0.26$, there is a left $\left(\mathrm{k}_{1}-\alpha\right)$ and right $\left(\mathrm{k}_{1}+\alpha\right)$ bounds. And after we find the left and right values of ki, we get both the left and right values of the fuzzy set $z$.

Then the algorithm in [20] is used. Based on the calculated $z$-value determines the probability of bankruptcy, $p=L_{6}(z)$ and using the membership functions of $I(p)$ is the index $i=I$ (p) and hence the lot to which $\widetilde{X}_{i}$ a company belongs, and scale in $\widetilde{X}_{i}$ a horizontal is a measure of the facilities $\mu_{\widetilde{X}_{i}}(p)$ for identifying the enterprise to the many in the system are organized according to the degree of fuzziness (trust) $\widetilde{X}_{2} \succ \widetilde{X}_{1} \succ \widetilde{X}_{3} \succ \widetilde{X}_{4}$

The further improvement algorithm is as follows: we set a random $\alpha$, which allows us to form sets of $\alpha$-levels of the fuzzy number $k_{l}$, find the right and left $z$ values of the Altman function, and observe how the choice of the right or left value affects the probability of bankruptcy of the enterprise.

\section{Algorithm}

In the general case of a fuzzy specification of all Altman coefficients $\left(k_{\mathrm{i}},(i=1, . ., 5)\right)$, the computational principle of the new model can in principle be described by the same sequence of steps:

1. We introduce fuzzy coefficients $k_{i}(i=1, . ., 5)$ for the Altman model with the assignment of the appropriate level of confidence $\alpha(1)$.

2. We calculate the left-side and right-side values of the
Altman function $\left(\mathrm{z}=\mathrm{Z}_{\mathrm{L}}\right.$ and $\left.\mathrm{z}=\mathrm{Z}_{\mathrm{R}}\right)$ by the formula (1).

3 . We determine the probability of bankruptcy of the enterprise using the sixth degree polynomial $\mathrm{p}_{\mathrm{L}}=\mathrm{L}_{6}\left(\mathrm{z}_{\mathrm{L}}\right)$ and $\mathrm{p}_{\mathrm{R}}=\mathrm{L}_{6}\left(\mathrm{z}_{\mathrm{R}}\right)$ (Figure 1).

4. We determine the indices $i_{L}=I\left(p_{L}\right)$ and $i_{R}=I\left(p_{R}\right)$ of fuzzy sets $\widetilde{X_{L i}}$ and $\widetilde{X_{R i}}(i=1, . ., 4)$ based on $\mathrm{p}_{\mathrm{L}}$ and $\mathrm{p}_{\mathrm{R}}$.

5. We conclude on the measure of fuzziness (level of confidence) according to $\mu_{\mathrm{AL}}(p)=d\left(\widetilde{X_{i L}}, X_{i 0 L}\right)$ and $\mu_{\mathrm{AR}}(p)=d\left(\widetilde{X_{i R}}, X_{i 0 R}\right)$, making a conclusion about the degree of fuzziness of the results obtained using a series $\tilde{X}_{2} \succ \tilde{X}_{1} \succ \widetilde{X}_{3} \succ \tilde{X}_{4}$.

This approach, with a single use, despite the presentation of more detailed information about the behavior of the model, may not accurately reflect the current situation at the enterprise, because only two different values of $\mathrm{z}_{\mathrm{L}}$ and $\mathrm{z}_{\mathrm{R}}$ are taken into account at a fixed confidence level $\alpha$. To more fully assess the feasibility of the method, we will resort to simulation and conduct multiple computational experiments with various random $\alpha$ with a uniform distribution law on the interval $[0,1]$.

\section{Conclusion}

The above-described mathematical model of the Altman method for assessing the creditworthiness of an enterprise with the procedure of continuous calculation of the probability of bankruptcy of enterprises, supplemented by fuzzy $k_{i}$ indicators, allows us to find the left-hand and righthand sets of $\alpha$-levels of the fuzzy set $k_{i}$ and observe how, with small changes in the coefficients, the probability of bankruptcy of an enterprise changes. In the proposed approach, the simulation modeling for incoming fuzzy economic indicators in the form of $\alpha$-sections of the fuzzy set is carried out to predict the impact of errors in the assessment of economic indicators on the conclusion of bankruptcy of the enterprise. 


\section{References}

[1] Baranovskaya T. P., Kovalenko A. V., Urtenov M. H., Karmazin V. N. (2009); Modern mathematical methods of analysis of financial and economic condition of the enterprise; monograph. Kubsau.

[2] Bakhvalov N. S. Numerical methods / H. S. Bakhvalov, N. P. Zhidkov, G. M. Kobelkov.-Moscow; Science, 1999.-630 p.

[3] Davydova G. V., Belikov A. Yu. (1999); Methods of quantitative risk assessment of banking enterprises //risk Management. No. 3.

[4] Diligenskii N., V., Dymova L. G., Sevastianov P. V. (2004); Fuzzy modelling and multi-objective optimization of production systems in conditions of uncertainty; Technology, Economy, Ecology M.; "Publishing house engineering-1".

[5] Dontsova, L. V. (2006); Analysis of financial statements Nikiforova.-4th ed., re-slave. and DOP. - M.; Business and Service.

[6] Zade L. (1976); the Concept of a linguistic variable and its application to approximate decision-making. M.; Mir.

[7] Zaitseva O. P. (1998); Crisis management in a Russian company//Siberian financial school. № 11-12.

[8] Ibrahimov. VA (2010); Elements of fuzzy mathematics. Baku, ASOA.

[9] Kovalenko A. V. (2009); Mathematical models and tools for complex assessment of financial and economic condition of the enterprise; Dis. kand. Econ. Sciences; 06.03.2009//Kuban state agrarian University.-Krasnodar.

[10] Konysheva L. K., Nazarov D. M. (2011); fundamentals of the theory of fuzzy sets. St. Petersburg; PI-Ter.

[11] Kofman A., Aluja H. Hill. (1992); Introduction of fuzzy set theory in enterprise management. Minsk; Higher school.

[12] Kuznetsov L. A., Carriers A. V. (2008); Assessment of credit history of individuals on the basis of fuzzy models//Management of large systems. Issue 21. M.; IPU ran.
[13] The Nedosekin A. O. (2004); Methodological foundations of modeling of financial activity with use of is indistinct-plural descriptions. Dis. dock. Econ. Sciences//SPb, Saint Petersburg state University-EF.

[14] Patlasov O. Yu. (2014); Application of Altman models and criteria in the analysis of the financial state of agricultural enterprises]//Financial management. №6, 2006. [Electronic resource]//-Access mode; URL; $\mathrm{http}$; //dis.ru/library/699/26221/.

[15] Pegat A. Fuzzy modeling and control/A. Pegat; lane from English.-2nd ed. (el.).-M.; BINOM. Knowledge laboratory, 2013.-798 p.

[16] Fomin, P. A. (2003); Features of accounting of financial risks at the forecast of dynamics of development of the economic entity. Finance and credit. No. 4.

[17] Kharin Y. S., malugin V. I. and V. P. Cirilica, Lubach V. I., Khatskevich G. A. (1997); Fundamentals of simulation and statistical modeling. Meganewton.; Design PRO.

[18] Shatalova A. Yu. Parametric $\alpha$-level $\lambda$-continuation method for fuzzy linear programming problem//A. Yu. Shatalova, K. A. Lebedev/"Bulletin of the Buryat state University. Mathematics, Informatics",-№ 1, 2018.

[19] Altman E. I., Iwanicz-Drozdowska M., Laitinen E. K., Arto Suvas Distressed Firm and Bankruptcy prediction in an international context; a review and empirical analysis of Altman's Z-Score Model//9.07.2014.

[20] Bamadio B., Lebedev K. A., Shevchenko I. V. (2016); Improvement of a five factor Altman model to assess the creditworthiness of an enterprise using the theory of fussy sets//Journal of Computations \& Modelling, vol. 6, № 4.

[21] Beaver W. (1967); Financial Ratio as Predictors of Failure, Empirical Research in Accounting//Journal of Accounting Research.-№ 4.

[22] Fulmer J. (1984); A Bankruptcy Classification Model For Small Finns//Journal of Commercial Bank Lending. № 6.

[23] Hiyama T., Sameshima T. (1991); Fuzzy logic control scheme for an-line stabilization of multi-machine power system//Fuzzy Sets and Systems. Vol. 39. 